\title{
Multiple sclerosis susceptibility in a Brazilian sample, HLA and CIITA genes
}

Estudo de associação entre a susceptibilidade à esclerose múltipla e fatores relacionados ao HLA

\author{
Eduardo Ribeiro Paradela
}

Resumo da Dissertação de Doutorado apresentada à Universidade Federal do Estado do Rio de Janeiro. Área de Neuroimunogenética. Rio de Janeiro RJ, Brasil.

Correspondence: Soniza Vieira Alves-Leon; Rua Mariz e Barros, 755; 20270-004 Rio de Janeiro RJ, Brasil; E-mail: neurogeneticarj@ig.com.br

Orientadoras: Soniza Vieira Alves-Leon e Carmen Lúcia Antão Paiva.

\begin{abstract}
Introduction: The multiple sclerosis (MS) is a chronic disease of the central nervous system that affects mainly young adults. This disease is characterized by the spread of demyelinating lesions in time and space. This condition may be influenced by genetic factors as heterogeneity, incomplete penetrance, polygenic inheritance and epigenetic factors, which makes this complex disease a challenge for geneticists. Objectives: The aim of this study was to investigate the association between HLA alleles from DQA1, DQB1 and DRB1 loci (6p21.3), genetic polymorphisms -168A/G (rs3087456) and $+1614 \mathrm{G} / \mathrm{C}$ ( $r$ 4774) in the CIITA gene (16p13) and susceptibility to MS in a miscegenated sample from Rio de Janeiro state, RJ, Brazil. Method: DNA samples from 52 patients with relapsing remitting multiple sclerosis (MSRR) [21 males (40.38\%) and 31 females (59.62\%)] and 116 healthy controls [46 males (39.65\%) and 70 females (60.35\%)] matched by race, sex and age were analyzed by techniques of PCR, SSP-PCR, electrophoresis and DNA sequencing. Results: A significant association between MS and HLA-DRB1*15:01 allele was observed [p value=.002; Odds Ratio $(O R)=3.2$, especially in women $(p=.001$; $\mathrm{OR}=4.9$ ), which remained statistically significant after Bonferroni correction. Furthermore, it was observed that the polymorphism $+1614 \mathrm{G} / \mathrm{C}$, "C/C" profile, in association with the allele DRB1*15:01 influences the increased susceptibility to MS in women ( $p=.029 ; 0 R=5.6)$. In addition, it was observed that the "G/G" profile in CIITA polymorphism +1614G/C may be associated with the resistance to MS ( $p=.02$; $\mathrm{OR}=0.23)$, as well as HLA-DRB1*11:02 ( $p=.02, \mathrm{OR}=0.5)$. The HLA-DQB1*06:02 allele also has been implicated as a possible susceptibility factor for $M S$ ( $p=.02 ; O R=1.8$, data not confirmed after Bonferroniás correction). Conclusion: Together, these results reinforce the polygenic nature of MS, and proposed that the CIITA gene, which is the regulator of the expression of HLA-D, is an additive factor to DRB1*15:01 allele, previously described as a genetic susceptibility factor to MS in Brazilians.
\end{abstract}

Keywords: CIITA gene, HLA, rs $4774 * \mathrm{C}, H L A-D R B 1 * 15: 01$, multiple sclerosis. 